bronght together with silk sutures. No provision was made for drainage. A dressing of boracic-acid powder and sal-alembroth gauze and wool was applied. The temperature reached $101.2^{\circ} \mathrm{F}$. on the day after the operation; it had fallen to $986^{\circ}$ by the following rlay; on the fifth day after the operation the temperature rose to $101 \cdot 8^{\circ}$ without any obvious cause ; with these exceptions the temperature kept about normal. The dressing was changed daily, as it either got shifted or soiled. The wound healed by first intention. The stitches were removed on the seventh day, and the child was discharged on the eighteenth day after the operation.

I was in some doubt as to how this case should be dealt with. The ovary and Fallopian tube might have been reduced if the abdominal ring had been very freely enlarged. They were, however, almost black from extravasated blood, and wore coated with lymph, but, as the inflammation was the result of strangulation, and quite independent of septic causes, they might doubtless have been returned into the abdomen without giving rise to a spreading peritonitis. On the other hand, they would probably have become adherent to the pelvic wall or some viscus, and might have given rise to subsequent trouble. And, further, the ovary appeared to be so much damaged by extravasation of blood into its substance as to render it of little or no physiological importance. After removal the ovary was found full of blood, which occupied several distinct cavities. The treat ment adopted was most probably the best.

Harley-street, $W$.

\section{CASE OF STRYCHNINE POISONING; RECOVERY.}

By HeRBERT C. W. JONES, M.B. CaNTaB., M.R.C.S.

ON June 10 th I was called at 11.5 A.M. to see A. B a night watchman, formerly a soldier, who was said to have been drinking heavily for a week, and to have "done something to himself" that morning. Going at once, I found the patient, a muscular man about thirty years of age, lying on his back in bed. Within a few seconds of my arrival he was seized with a tetanic convulsion, opisthotonos being well marked, the arms flexed across the chest in a condition of rigid tremor, with the hands clenched and the legs extended. His face was livid and congested, and his features were fixed in a spasmodic grin. At the onset of the paroxysm he gave an agonised shriek, which ceased as the respiratory muscles became involved in the spasm. This paroxysm lasted nearly two minutes, and during its continuance the pupils were considerably dilated. Suspecting strychnine poisoning, I questioned him (his mind in the interval being quite clear), and he confessed to having swallowed two threepenny packets of Battle's vermin.killer at 10.45 that morning. After an interval of about three minutes, during which muscular twitchings occurred almost continuously, another, violent paroxysn supervened, followed rapidly by others, all of the same character, more than one of which threatened to be fatal from asphyxia. Finding that the slightest touch at once brought on an attack, I judged that any attempt to wash out the stomach or produce emesis would very likely prove fatal, and having by this time (11.30 A.M.) procured chloral hydrate, twenty grains dissolved in water were injected subcutaneously during an attack. At midday the attacks were rather less frequent, but still very severe, so another twenty grains of chloral were injected hypodermically during an attack. The intervals between the successive attacks now became about ten minutes, and at 1 P.M. ten grains more of chloral were injected. Between 1 and 2 o'clock he had only three paroxysms. He complained of great thirst throughout, but the attempt to swallow brought on an attack. Towards 3 P.M., soon after a paroxysm, he swallowed some water and was given twenty grains of chloral by the mouth. After this he had no more attacks, but the muscular twitchings still continued until about 7 P.M. Soon after 3 P.M. he retched several times, but only brought up a little frothy mucus. From 7 P.M. to 8 P.M. he slept, and woke feeling very weak and sore in the arms and back. From this time he rapidly recovered, and was able to go out in three days. He tells me that on Sunday, June 9th, he swallowed the contents of two threepenny packets of the

vermin-killer, but vomited immediately, and felt no ill effects. On Monday, the 10 th, he breakfasted at 4 A.M., and bought two threepenny packets of the same verminkiller at a chemist's, who confirms his statement. He was in the habit of getting it there to destroy rats on the premises where he is employed. He then drank some ale and spirits, went home, and, emptying the packets into a glass of water, swallowed them, leaving none in the glass. This was at $10.45 \mathrm{~A} . \mathrm{M}$. He almost immediately felt faint and went to bed, the convulsions beginning in about five minutes. He did not vomit. The threepenny packet of this vermin-killer contains about fourteen grains, and, according to Dr. Letheby's analysis, 23 per cent. of this is strychnine; therefore, assuming the man's account to be true (which I see no reason for doubting), he must have taken about six grains of strychnine in the two packets. Whether the alcohol he had taken in any way modified the action of the poison I will not venture to say, but the case appears to me interesting, as confirming the fact that in chlorate hydrate we possess a reliable antidote to strychnine. Chelsea.

\section{dy attirtror}

OF

\section{HOSPITAL PRACTICE,} BRITISH AND FOREIGN.

Nulla autem est alia pro certo noscendi via, nisi quamplurimas et mor. borum et dissectionum historias, tum aliorum tum proprias collectas habere, et inter se comparare.-MorgagnI De Sed. et Caus. Morb., lib. iv. Proœmium.

\section{GUY'S HOSPITAL}

A CASE OF LEPROSY; LARYNGEAL OBSTRUCTION ; TRACHEO. TOMY ; DEATH ; NECROPSY.

(Under the care of Dr. FREDERICK TAYLOR and the late Dr. WOOLDRIDGE.)

Mucr attention has been given to the subject of leprosy during the last few weeks, more especially to the question of its contagiousness. Wo have fully discussed this point in our columns, ${ }^{1}$ as also the various causes which have led to this unusual interest in the disease. We do not therefore propose to reconsider these points, but to put before our readers the account of a case which was under skilled observation in England. As this observation extended over many years, it would not be possible to give the full history of the case, but the following account will be found interesting, as the disease is rare in this country, and post-mortem records of it are not frequently to be obtained. The disease appears to have developed in a boy, the son of healthy European parents, which is very unusual, and to have commenced at an earlier age than is commonly found, the first symptoms generally appearing about the age of puberty, or in early adult life. 'The course of the disease presents nothing of a remarkable character, excepting for the pyrexia, until the onset of the lanyngeal symptoms. On the occurrence of these complications Ur. Vandyke Carter says:" "There is one occasion of death which is in its way also peculiar, and is only men tioned by the Norwegian physicians. I mean that entered as 'Laryngitis and Suffocation,' which had occasioned fifteen casualties (out of 300); and on inquiry during my late visit to Bergen, I ascertained that this event was sometines a very sudden one in leprosy; but whether the laryngeal disease causing suffocation is always leprous, or is sometimes strumous remained uncertain. The possibility of sudden asphyxia in lepers is well known to surgeons in India." That a large number of cases of leprosy die from phthisis is well known, and Dr. Beavan N. Rake has exhibited at the Pathological Society ${ }^{3}$ specimens from a case of mingled tubercular and anæsthetic leprosy, demonstrating the occasional presence of tubercular disease of the larynx in leprosy. There is usually no fever ; Dr. Vandyke Carter" also adds: "From this table

I THE LANCET, vol. i., 1889, p. 1309.

2 Report on Leprosy to the India Office, 1874, p. 143. 3 Path. Soc. Trans., 1886 , p. 544

4 Fagge's Practice of Medicine. ${ }_{5}$ Op. cit., p. 143. 